\title{
Urinary protein profiles in ketorolac-associated acute kidney injury in patients undergoing orthopedic day surgery
}

This article was published in the following Dove Press journal: International Journal of Nephrology and Renovascular Disease 18 September 2017

Number of times this article has been viewed

\author{
Filippo Mariano' \\ Chiara Cogno' \\ Fulvia Giaretta ${ }^{2,3}$ \\ Ilaria Deambrosis ${ }^{2,3}$ \\ Simona Pozza ${ }^{4}$ \\ Maurizio Berardino 5 \\ Giuseppe Massazza ${ }^{6}$ \\ Luigi Biancone ${ }^{1,3}$
}

'Department of General and Specialist Medicine, Nephrology, Dialysis and Transplantation Unit, City of Health and Science, CTO Hospital, Turin, ${ }^{2}$ Department of General and Specialist Medicine, Laboratory of Nephrology and Immunopathology, City of Health and Science, Molinette Hospital, Turin, ${ }^{3}$ Department of Medical Sciences, University of Turin, Turin, ${ }^{4}$ Department of Radiology and Radiotherapy, CTO Radiology, City of Health and Science, CTO Hospital, Turin, ${ }^{5}$ Department of Anesthesiology and Intensive Care, Anesthesiology and Intensive Care 5, City of Health and Science, CTO Hospital, Turin, ${ }^{6}$ Department of Orthopedics and Traumatology, Week Hospital Unit, City of Health and Science, CTO Hospital, and University of Turin, Turin, Italy

Correspondence: Filippo Mariano Department of General and Specialist Medicine, Nephrology, Dialysis and Transplantation $U$, City of Health and Science, CTO Hospital, Via G. Zuretti 29 10126 Turin, Italy

$\mathrm{Tel}+39$ | | 6933674

Fax +39 || 6933672

Email filippo.mariano@hotmail.it
Background: Parenteral administration of ketorolac is very effective in controlling postoperative pain for orthopedic surgery. Ketorolac can induce clinically relevant renal alterations in elderly patients, whereas its short course is considered safe for young adults with normal preoperative renal function. In this study, of a cohort of young adults undergoing elective orthopedic day surgery, we sought cases complicated by readmission due to acute kidney injury (AKI).

Patients and methods: Among 1397 young adults, aged 18-32 years who were admitted to undergo orthopedic day surgery from 2013 to 2015 , four patients $(0.29 \%$, three males/one female) treated in postprocedure with ketorolac (from 60 to $90 \mathrm{mg} /$ day for 1-2 days) were readmitted for suspected severe AKI. We evaluated functional outcome, urinary protein profiles and kidney biopsy (1 patient).

Results: After day surgery discharge, they experienced gastrointestinal disturbances, flank pain and fever. Readmitted on post-surgery days 3-4, they presented with oliguric AKI (creatinine range 158.4-466.4 $\mu \mathrm{mol} / \mathrm{L}$ ) and frank proteinuria (albumin range 2.1-6.0 g/L). Urine protein profiles demonstrated a nonselective glomerular proteinuria, with a significant 9.4 -fold increase in glomerular/tubular index on day 6. Kidney biopsy on day 19 showed normal glomeruli and minimal tubular alterations and negative immunofluorescence. All patients recovered their renal function, and after 20 days proteinuria disappeared.

Conclusion: AKI can ensue even in young adults who have undergone a short course of ketorolac, when they suffered from relative dehydration, abdominal disturbances, flank pain and oliguria after discharge. Urine findings were characterized by a marked nonselective glomerular proteinuria disappearing in 2-3 weeks.

Keywords: ketorolac, acute kidney injury, glomerular tubular index, orthopedic day surgery

\section{Introduction}

Ketorolac is a widespread drug in the management of postoperative pain after a shortstay elective orthopedic surgery. ${ }^{1}$ Parenteral administration is very effective, allowing a positive opioid-sparing effect. ${ }^{1,2}$

Apart from acute interstitial nephritis, an immunological reaction with defined histological alterations, ketorolac can induce a continuum of renal functional alterations, changing from a frank picture of oliguric acute kidney injury (AKI) to some minor injuries, such as decreased renal plasma flow (RPF) and glomerular filtration rate (GFR), dysfunction in salt and water handling and in renin release by the juxtaglomerular apparatus. ${ }^{3,4}$ However, in adults with normal preoperative renal function, short course of ketorolac is considered safe, and not leading to postoperative AKI. ${ }^{4}$ In controlled 
studies, $60 \mathrm{mg}$ /day parenteral course of ketorolac for 2 days showed only a minimal decrease in potassium excretion, ${ }^{5}$ and only a transient reduction in renal function has been reported in young adults in the early postoperative period. ${ }^{4}$

In this article, we sought, in a cohort of young adults undergoing elective orthopedic day surgery, the cases complicated by readmission due to AKI. We evaluated the renal functional alterations, the urinary protein profiles and in 1 patient the renal histology.

\section{Patients and methods}

From 2013 to 2015,6349 patients were admitted to undergo orthopedic day surgery at CTO Hospital. All these patients were ordinarily discharged within 48 hours. Among these patients, we sought the patients readmitted to hospital for any complication within 1 week. We retrieved 38 patients, and among those 4 patients ( 3 males/ 1 female, aged 18-32 years; Table 1) were readmitted for a severe picture of AKI. These 4 AKI patients represented a $0.29 \%$ of 18-32-year-old 1397 young adults.

All 4 patients had normal preoperative serum creatinine, and no previous history of renal disease. In addition, before surgery, all were classified in stage I-II American Society of Anesthesiology (ASA physical status classification system). ${ }^{6}$ According to the postprocedure antalgic protocol, they were treated with ketorolac (from 60 to $90 \mathrm{mg} /$ day for 1-2 days), and other analgesic (paracetamol, tramadol; Table 1). On day 2, they were regularly discharged.

On the next day, at home they experienced vomiting (one case), nausea, epigastralgia, flank pain and fever (3 patients; Table 1), and they were readmitted on days 2-3.

During readmission stay, the 4 AKI patients were routinely monitored for urine output and blood pressure. Laboratory studies included urinalysis, 24-hour collection for urinary protein and albumin, complete blood counts, serum creatinine, urea, electrolytes, liver enzymes, albumin, immunological screening (complement fractions, antinuclear antibodies, immunoglobulin, anti-DNA) and urine samples for protein markers.

Urine sample study included urinary protein profiles by electrophoresis, and nephelometric quantification of specific glomerular (albumin, transferrin, immunoglobulin $\mathrm{G}$, alpha-2-macroglobulin) and tubular (retinol-binding protein, alpha-1-microglobulin) marker proteins. Then, the analysis of marker proteins was performed by MDI-LABLINK software. ${ }^{7}$

Renal ultrasonography was performed for all patients.

All 4 patients were treated with intravenous (i.v.) crystalloids, furosemide and all other drugs when needed. As part of standard care, patient (case 1) underwent percutaneous kidney biopsy on day 19 .

As to specific therapy, 3 out of 4 patients underwent a short course of corticosteroids ( $3 \mathrm{mg} / \mathrm{kg}$ /day of methylprednisolone i.v. for 3 days).

Informed consent was given by the 4 patients whose case details are described in the study. They have provided written informed consent for the case details to be published.

Values were expressed as median (interquartiles).

\section{Results}

At readmission, all patients presented with signs of mild dehydration (median 3.2\% of weight loss), 3 were oliguric and 1 anuric. No patient had symptoms or signs of allergy (rash, itching or eosinophilia). Biochemical data demonstrated a picture of severe AKI, with increased creatinine (range 135.5-243.0 $\mu \mathrm{mol} / \mathrm{L}$ ).

Urine analysis showed frank albuminuria, in the absence of leukocyturia and/or microscopic hematuria. On the other hand, in 3 out of 4 patients, granular and cellular cast were occasionally present, with renal cells in case 1 (Table 1).

Renal ultrasonography revealed enlarged kidneys with hyperechogenic parenchyma.

Table I Clinical data of patients

\begin{tabular}{|c|c|c|c|c|c|c|c|}
\hline $\begin{array}{l}\text { Patient } \\
\text { no. }\end{array}$ & $\begin{array}{l}\text { Age } \\
\text { (years)/ } \\
\text { sex }\end{array}$ & Surgery & $\begin{array}{l}\text { ER access } \\
\text { (days) }\end{array}$ & $\begin{array}{l}\text { Symptoms before } \\
\text { AKI ( } T^{\circ} \text { peak } C / \text { day } \\
\text { of peak) }\end{array}$ & $\begin{array}{l}\text { Ketorolac } \\
\text { (mg/day) } / \\
\text { therapy (days) }\end{array}$ & $\begin{array}{l}\text { Other drugs } \\
\text { (mg/day) }\end{array}$ & Urinary findings \\
\hline I & $27 / M$ & $A C L$ surgery & 3 & $\begin{array}{l}\text { Epigastralgia, flank } \\
\text { pain, fever (39.3/third) }\end{array}$ & $90 / 2$ & $\begin{array}{l}\text { Paracetamol ( } 3000) \text {, } \\
\text { morphine }(30)\end{array}$ & $\begin{array}{l}\text { Few renal cells, few } \\
\text { granular casts, few cellular } \\
\text { casts, some hyaline casts }\end{array}$ \\
\hline 2 & $18 / F$ & $\begin{array}{l}\text { Malleol tibial } \\
\text { fracture }\end{array}$ & 4 & $\begin{array}{l}\text { Epigastralgia, fever } \\
\text { (37.5/second) }\end{array}$ & $60 / 1$ & Tramadol (100) & Few hyaline casts \\
\hline 3 & $31 / M$ & $\begin{array}{l}A C L+M C L \\
\text { surgery }\end{array}$ & 4 & Epigastralgia, flank pain & $60 / 2$ & $\begin{array}{l}\text { Paracetamol (4000), } \\
\text { tramadol (200) }\end{array}$ & $\begin{array}{l}\text { I cellular cast, I granular } \\
\text { cast, some hyaline casts }\end{array}$ \\
\hline 4 & $32 / M$ & $A C L$ surgery & 3 & $\begin{array}{l}\text { Flank pain, fever } \\
\text { (37.5/second) }\end{array}$ & $60 / 2$ & $\begin{array}{l}\text { Paracetamol }(3000), \\
\text { tramadol }(100)\end{array}$ & No significant alterations \\
\hline
\end{tabular}

Abbreviations: ACL, anterior cruciate ligament; AKI, acute kidney injury; ER, Emergency Room; MCL, medial collateral ligament. 
Immunological screening performed in the following days was within normal limits for all patients.

Creatinine maximally peaked in case 1 at $466.4 \mu \mathrm{mol} / \mathrm{L}$ on day 5 (Figure 1, upper left panel). Urine albumin (range 2.1-6.0 g/L) decreased over days for all patients, whereas urine volume simultaneously increased (Figure 1). Total proteinuria median values were $1.60(0.64-2.20), 0.68$ (0.45-0.90), $0.21(0.16-0.26)$ and $0.26(0.17-0.35) \mathrm{g} /$ day (interquartiles) on days 6, 9, 12 and 18, respectively.

Analysis of marker proteins (MDI-LABLINK software) ${ }^{7}$ demonstrated a nonselective glomerular type of proteinuria. On day 6, median glomerular/tubular index increased significantly up to 9.4 times (Figure 2, lower panel), and albumin was the most part of proteinuria (Figure 2, upper panel). Proteinuria, albuminuria and glomerular/tubular index returned to baseline after day 20 (Figure 2, upper and lower panel). Serum creatinine has decreased from 6 days onward for all 4 patients (Figure 1).

Light microscopy on bioptic samples showed glomeruli with normal aspect and mostly normal tubular cells. However, only in few medullary and cortical tubules, accumulation of Tamm-Horsfall protein was seen within the lumen in association with macrophages, some of which plurinucleated. Small caliber arterial vessels had small parietal hyaline plaques,
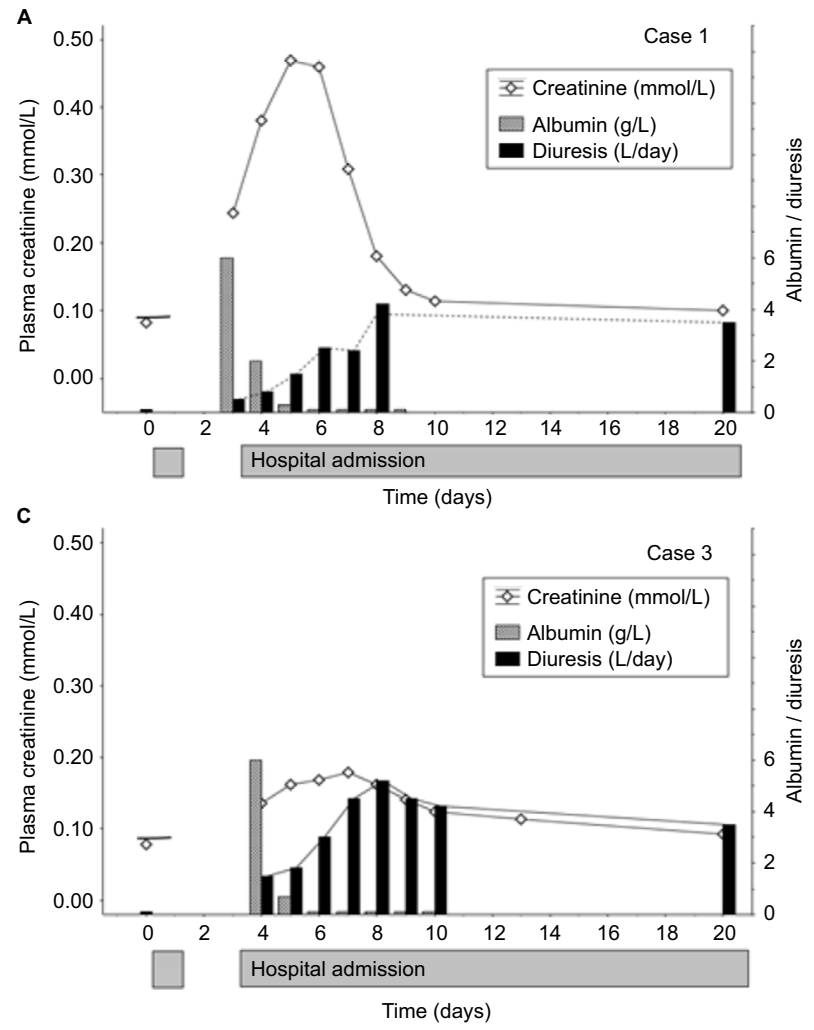

while those of greater caliber showed discrete intimal fibrosis. Immunofluorescence studies were negative.

\section{Discussion}

Orthopedic day surgery patients treated with a short course of ketorolac and regularly discharged could be at risk of developing AKI when at home if they had present symptoms like fever, epigastralgia or bilateral flank pain. Ketorolac-associated AKI is a rare complication, but it can severely affect renal function and cause glomerular proteinuria.

Soon after its availability on the market in 1992, several reports showed concerns about cases of postoperative ketorolac-associated AKI. However, in the following years, post-market experience and more information have demonstrated the benefits of ketorolac in clinical practice, without a clear evidence on an additive risk in postoperative AKI. ${ }^{4,8}$ A wide retrospective cohort of patients including over 10,000 courses of ketorolac for 2 days in 35 hospitals evaluated the AKI incidence in post-surgery. It showed an AKI incidence value as low as $1.1 \%$ for treated ketorolac patients. Of more, a comparison for the risk of AKI between parenteral ketorolac and opioids showed no significant difference. ${ }^{8,9}$ In that report, ${ }^{9}$ AKI was defined as a peak serum creatinine concentration
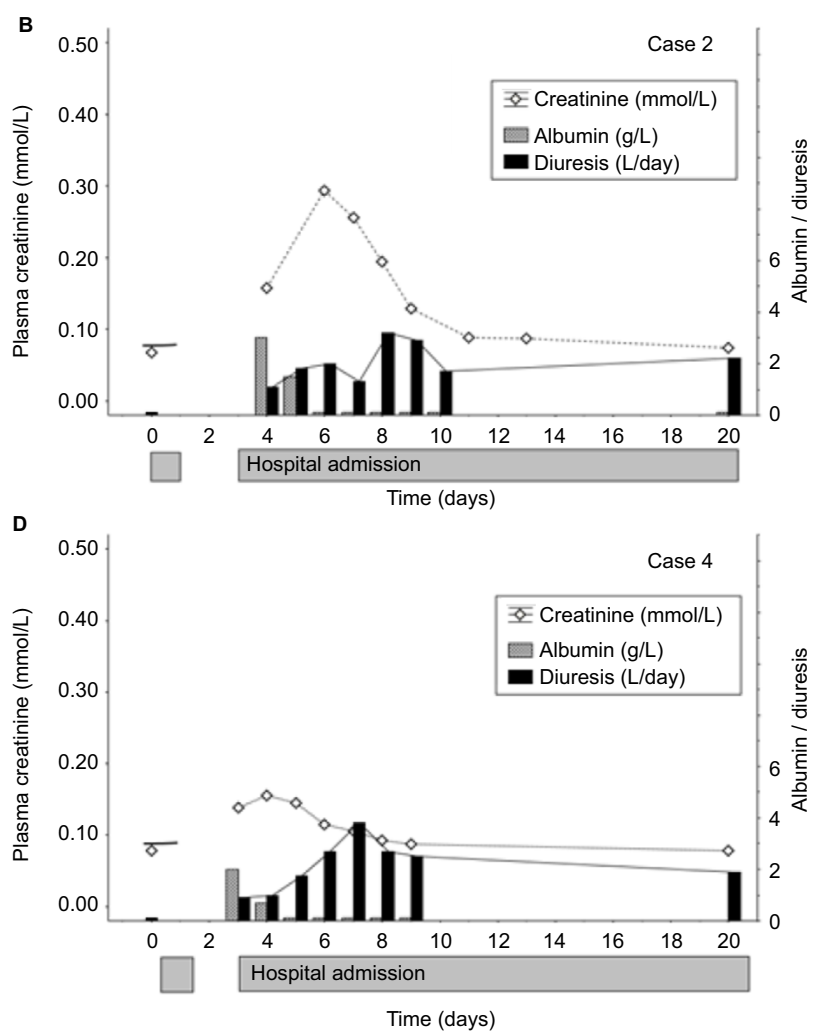

Figure I Pattern of plasma creatinine (mmol/L), urine albumin $(\mathrm{g} / \mathrm{L})$ and urine volume $(\mathrm{L} /$ day) for each of the 4 studied patients $(\mathbf{A}-\mathbf{D})$. Note: Data are shown over the first 20 days after surgical procedure. 

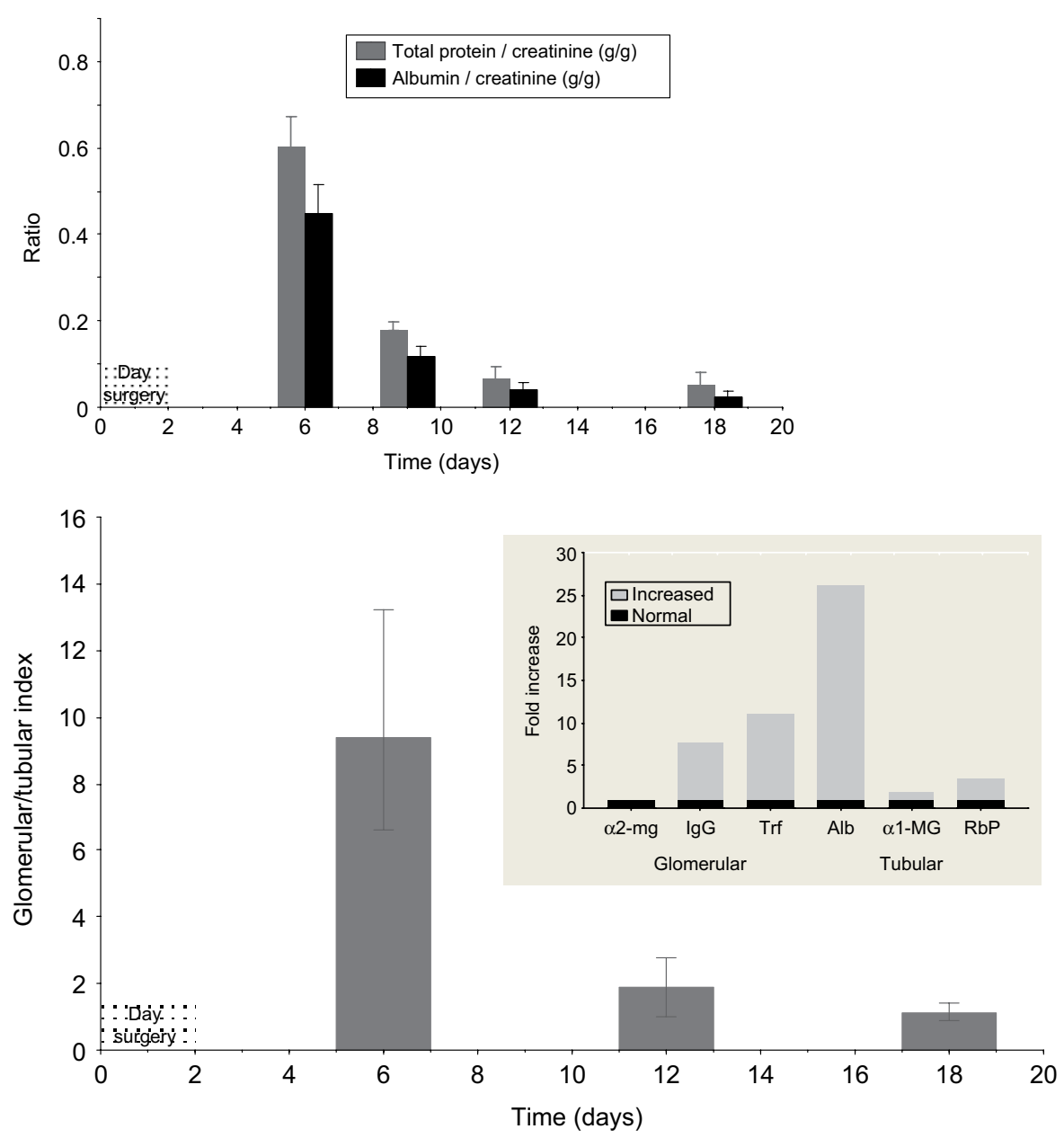

Figure 2 Protein/creatinine ratio and glomerular-tubular index over the first 20 days.

Note: Upper panel shows an early marked increase in proteinuria and albuminuria, which decreased over days. Lower panel shows the pattern of glomerular/tubular index, which increased 9.4-fold on day 6, then decreased until its normalization on day 20. Insert: urinary marker patterns of case I on day 6. The protein markers such as $\alpha 2-M G$, IgG, Trf, Alb, $\alpha$ I-MG, RbP are represented by different columns distributed according to their molecular weight, and grouped in glomerular and tubular markers. Increased values (gray bars) are expressed as multiple of the upper reference limit (black bars). Glomerular/tubular index results from the ratio between relative increase in glomerular proteins and relative increase in tubular proteins. ${ }^{7}$

Abbreviations: Alb, albumin; $\alpha$ I-MG, alpha-I-macroglobulin; $\alpha 2-M G$, alpha-2-macroglobulin; IgG, immunoglobulin G; RbP, retinol-binding protein; Trf, transferrin.

$50 \%$ greater than the baseline value, or a notation in the hospital chart that acute renal failure had occurred during the course of analgesic therapy. ${ }^{9}$

In our experience, the incidence of reported AKI was as low as $0.29 \%$. However, our patients were different, as they were healthy and young adults, without any known preoperative risk factors for $\mathrm{AKI},{ }^{3,5}$ and not in ordinary admission but in day surgery. In effects, after day surgery discharge, all patients reported to have had abdominal symptoms such as epigastralgia, bilateral flank pain, nausea, vomiting and fever (Table 1). Abdominal symptoms were likely due to gastrointestinal toxicity of ketorolac itself. As for fever, early postoperative pyrexia is a phenomenon often associated with knee surgery. It is believed to be due to surgical trauma and sustained by local and systemic release of endogenous proinflammatory mediators (complement products, IL-1 $\beta$, IL-6 and TNF- $\alpha$ ). ${ }^{10}$ In our patients, both gastrointestinal disturbances and fever could result in a loss, and/or inadequate consumption of fluids. All these factors favored an underlying volume depletion and reduced renal perfusion. As patients kept taking ketorolac, the inhibition of prostaglandin synthesis could cause a deep and prolonged renal ischemia, resulting in oliguric AKI. ${ }^{3-5}$ Interestingly, in subjects very susceptible to dehydration such as children, AKI onset has also been described after nonsteroidal anti-inflammatory drug (NSAID) administration taken for fever due to gastroenteritis, or infectious diseases, ${ }^{11}$ or for headache, dysmenorrhea and suicidal attempt. ${ }^{12}$

In the first days, we found a marked proteinuria, of glomerular type and nonselective. After 9-12 days, glomerular 
proteinuria disappeared leaving a minor tubular component. Proteinuria reflected an increased glomerular permeability, likely due to generation of inflammatory mediators triggered by the initial ketorolac-induced ischemic injury. In effects, at admission, all patients experienced bilateral flank pain, and ultrasonography revealed enlarged kidneys. In humans, the target enzymes of ketorolac, COX-1 and COX-2, are present in parenchymal kidney cells, including podocytes, mesangial, macula densa and cortical thick ascending limb cells. ${ }^{13}$ COX inhibitors such as ketorolac can induce renal phlogosis by a number of different mechanisms, such as a shunt of arachidonic acid from COX to LOX pathway with an exaggerated synthesis of peptidoleukotrienes LTD4 capable of preglomerular vasoconstrictor activity, ${ }^{3-5,14}$ or a block of specific enzymes that inactivate leukotrienes. ${ }^{14}$ Of more, in a sheep model of NSAID-associated AKI with proteinuria and increased creatinine, protein leakage in the glomeruli was associated with activation of complement cascade pathway in urine, ${ }^{15}$ which in turn amplified the injury on tubular cells via inflammatory and fibrinogenic pathways. $^{16}$

As an outcome, all 4 patients fully recovered renal functions in 3-6 weeks. This favorable outcome is consistent with no significant histological alterations on kidney biopsy 19 days after the kidney injury.

\section{Conclusion}

Reported data show that ketorolac-associated AKI is a rare, but severe early complication. It can ensue even after a short course of ketorolac in young adult patients, when they suffer from dehydration after discharge. This form of AKI was characterized by a marked nonselective glomerular proteinuria with a minor tubular component.

\section{Author contributions}

All authors contributed toward data analysis, drafting and critically revising the paper and agree to be accountable for all aspects of the work.

\section{Disclosure}

The authors report no conflicts of interest in this work.

\section{References}

1. Williams JS Jr, Wexler G, Novak PJ, Bush-Joseph CA, Bach BR Jr, Badrinath SK. A prospective study of pain and analgesic use in outpatient endoscopic anterior cruciate ligament reconstruction. Arthroscopy. 1998;14(6):613-616.

2. Ready LB, Brown CR, Stahlgren LH, et al. Evaluation of intravenous ketorolac administered by bolus or infusion for treatment of postoperative pain. A double-blind, placebo-controlled, multicenter study. Anesthesiology. 1994;80(6):1277-1286.

3. House AA, Silva Oliveira S, Ronco C. Anti-inflammatory drugs and the kidney. Int J Artif Organs. 2007;30(12):1042-1046.

4. Lee A, Cooper MG, Craig JC, Knight JF, Keneally JP. Effects of nonsteroidal anti-inflammatory drugs on postoperative renal function in adults with normal renal function. Cochrane Database Syst Rev. 2007;(2):CD002765.

5. Reinhart DI. Minimising the adverse effects of ketorolac. Drug Saf. 2000;22(6):487-497.

6. ASA [webpage on the Internet]. ASA Physical Status Classification System. Available from: https://www.asahq.org/resources/clinical-information/ asa-physical-status-classification-system. Accessed October 31, 2016.

7. Regeniter A, Freidank H, Dickenmann M, Boesken WH, Siede WH. Evaluation of proteinuria and GFR to diagnose and classify kidney disease: systematic review and proof of concept. Eur J Intern Med. 2009;20(6):556-561.

8. Myles PS, Power I. Does ketorolac cause postoperative renal failure: how do we assess the evidence? Br J Anaesth. 1998;80(4):420-421.

9. Feldman HI, Kinman JL, Berlin JA, et al. Parenteral ketorolac: the risk for acute renal failure. Ann Intern Med. 1997;126(3):193-199.

10. Andres BM, Taub DD, Gurkan I, Wenz JF. Postoperative fever after total knee arthroplasty: the role of cytokines. Clin Orthop Relat Res. $2003 ;(415): 221-231$.

11. Krause I, Cleper R, Eisenstein B, Davidovits M. Acute renal failure, associated with non-steroidal anti-inflammatory drugs in healthy children. Pediatr Nephrol. 2005;20(9):1295-1298.

12. Ulinski T, Guigonis V, Dunan O, Bensman A. Acute renal failure after treatment with non-steroidal anti-inflammatory drugs. Eur J Pediatr. 2004;163(3):148-150.

13. Gambaro G, Perazella MA. Adverse renal effects of anti-inflammatory agents: evaluation of selective and nonselective cyclooxygenase inhibitors. J Intern Med. 2003;253(6):643-652.

14. Clish CB, Sun YP, Serhan CN. Identification of dual cyclooxygenaseeicosanoid oxidoreductase inhibitors: NSAIDs that inhibit PG-LX reductase/LTB(4) dehydrogenase. Biochem Biophys Res Commun. 2001;288(4):868-874.

15. Palviainen MJ, Junnikkala S, Raekallio M, Meri S, Vainio O. Activation of complement system in kidney after ketoprofen-induced kidney injury in sheep. Acta Vet Scand. 2015;57:15.

16. Biancone L, David S, Della Pietra V, Montrucchio G, Cambi V, Camussi G. Alternative pathway activation of complement by cultured human proximal tubular epithelial cells. Kidney Int. 1994;45(2):451-460. 
The International Journal of Nephrology and Renovascular Disease is an international, peer-reviewed open access journal focusing on the pathophysiology of the kidney and vascular supply. Epidemiology, screening, diagnosis, and treatment interventions are covered as well as basic science, biochemical and immunological studies. The manuscript management system is completely online and includes a very quick and fair peer-review system, which is all easy to use. Visit http://www. dovepress.com/testimonials.php to read real quotes from published authors.

Submit your manuscript here: https://www.dovepress.com/international-journal-of-nephrology-and-renovascular-disease-journal 